\title{
Vestigios neobarrosos: \\ Nestor Perlongher \\ y Osvaldo \\ Lamborghini
}

Neo-Baroque Vestiges:

Nestor Perlongher and

Osvaldo Lamborghini

Nancy Fernàndez

UNMdP-CONICET 


\section{Resumen}

En este trabajo intento trabajar las nociones teóricas de tradición y uso en función de dos poetas de la neovanguardia argentina: Nestor Perlongher y Osvaldo Lamborghini. Aquí procuro desarrollar, en algunos de sus textos, el sentido de la política y la violencia inscripta en sus poéticas, analizando los procedimientos que las particularizan.

Palabras claves: Literatura; Tradición; Violencia

\section{Abstract}

In this work I try to work on the theoretical notions of tradition and use based on two poets of the Argentine neo-avant-garde: Nestor Perlongher and Osvaldo Lamborghini. Here I try to develop in some of his texts, the sense of politics and violence inscribed in his poetics, analyzing the procedures that particularize them.

Keywords:

Literature; Tradition; Politic; Violence 
La lengua de la nación tiene que ver, menos con el idioma hegemonizado por el repertorio lexical del diccionario, que por los usos y prácticas políticas, asumidas como las estrategias culturales de inscripciones diferenciales. La literatura, en este sentido, adviene para constituir sus modos de decir a través del espacio de la letra, allí donde se configuran los imaginarios (ideológicos, históricos y políticos) a través de aquellas textualidades donde la violencia instala su motivación y su forma. Sin embargo, los usosconfronta frente a la respuesta útil de los servicios prestados por aquellos autores ligados a los proyectos nacionales de la coalición oligárquica-liberal. Desde esta perspectiva, si las operaciones instrumentadas por Leopoldo Lugones o por Ricardo Rojas hacia el Centenario argentino se muestran solventes en calidad de representaciones totalizantes, el tiempo sentencia su efectividad con la canonización de sus autores y sus géneros. Sin duda, tamañas construcciones enciclopedistas, apelan a dar respuesta y crédito institucional. Pero a medida que el siglo XX avanza en su transnacionalización, los proyectos del estado asisten a la erosión de sus fronteras en procesos culturales y económicos, cuyos resultados se aceleran con los avances de la cultura de masas, la industria de las comunicaciones y la tecnología. Las configuraciones de las subjetividades históricas se modifican y desplazan el área de lo sensible según las coordenadas de espacio y tiempo, tendiendo a la fragmentación. También las disputas y confabulaciones, por el territorio de lo visible, van permitiéndose hacer foco en motivos y detalles, crípticos y gradualmente desligados de aquellos programas impartidos por el estado. Literatura y arte se permiten, o mejor, demandan, anclar en aquellas zonas intersticiales de la cultura a través de sus aspectos menos expuestos, menos "útiles" o alineados a una teleología prescripta de manera vertical. Pero lo cierto es que, desde su período fundacional en el siglo XIX, la literatura argentina siempre franqueò los limites de lo que el poder faccioso consideraba conveniente: léanse, sino, el sentido que inscribe un texto como El matadero, de Esteban Echeverrìa, o el Facundo: Civilización y Barbarie, de Domingo Faustino Sarmiento. La lengua, entonces, no es un factor ajeno a los cambios y las mutaciones sino la materia misma donde se hacen visibles las transformaciones más sutiles, y la literatura, un modo de registrar y de descartar también la potencialidad de la escritura. En el siglo XX, Perlongher y Lamborghini son exponentes de las operaciones estéticas más extremas entre los bordes de la prosa y la poesía. $\mathrm{Y}$, en ambos autores, la política y su violencia certifican los efectos irreductibles de la lengua, suscripta al carácter activo, dinámico de la tradición y del uso.

Nestor Perlongher construye una Eva Perón devenida; de reina amortajada a mandataria de ultratumba, de prostituta a diosa y viceversa sin que medien los valores culturales ni la moral de conjunto. La oralidad, vuelve así como respuesta interpelada, no como acatamiento al mandato sino como engarce de una nueva pregunta encubierta por un deseo inconveniente. La curiosidad y el anhelo, el rencor y la lujuria que arrastra 
el recuerdo del cuerpo con vida, rodando ahora en féretros clandestinos pero objeto del equívoco decoro del embalsamador. Otra vez, o mejor, siempre, la ironía en la inestabilidad del signo, cuando el juego macabro con la piel traslúcida, se funde con los velos y el olor de las orquídeas descompuestas. Con sus atributos, en Evita resuenan con desvíos las reinas y madres de Lezama Lima, la adúltera Gertrudis (reina y madre de Hamlet) y la voluptuosa Reina de la Noche que en La flautamágica (de Mozart y Schikaneder) que luego de su muerte promete volver al final de cada día. El epígrafe de Lezama Lima se transforma en una nueva pregunta irónicamente retórica; “ huyo de la madre de Lezama Lima? la hago pedazos?" (46).(referencia a un texto de Lezama Lima)

Lo que en "El Cadáver" se muestra como despunte insidioso, como curiosidad impertinente e insubordinada, o eso que aparece como atisbo de perversión pueril ("arañazos del embalsamador en los tejidos"; "y si no nos tomáramos tan a pecho su muerte, digo") ya en "El Cadáver de la Nación" se erigen la reliquia y la blasfemia, la liturgia efectiva de un grotesco donde lo que yace se figura hipostasiado con las minorías que devienen su potencia multiplicada. De la renuencia equívoca, del deseo insurrecto escindido en el saber de la culpa, de aquí en más la técnica del ritmo y del verso dedica su orfebrería a la decoración macabra de la muerta, a la muerte nimbada como cuerpo rodante que abomina del silencio y del vacío. Ella se perpetúa así, inmortalizada en la vigilia de un entierro sin fin, en la exuberancia de la vida y de la muerte. Y en esa estereofonía pronominal (yo, tu, nosotras, ellos), acatan el influjo de una sordidez deseada; anhelo atávico en el "pasillo" que sigue la multitud. En otro texto, me refería los usos potenciados en las mitologías, las lecturas y las representaciones que generan figuraciones de la sensibilidad, política, social, cultural a través de la Historia. Así asistimos al entierro multitudinario, a la desaparición del cadáver, la conservación artificial del cuerpo que certifica la creencia en alguna forma de inmortalidad, a la voz radial que anunciaba el paso hierático ante la mirada colectiva y popular; Perlongher adelgaza al extremo la línea entre eros y tanatos. El punto de inflexión es la bisagra que desarticula el folklore salvaje del bajo fondo urbano que actualiza la clave sentimental del origen espurio: la pobreza, el temblor que une al general con una actriz, la seducción de una "princesa de maneras ordinarias", del resentimiento a la revancha estridente, del no tener a los vestidos de diva. Atuendos y joyas como astillas del propio cuerpo que será reliquia devenida en millones de ojos que aguardan la imagen del cabello suelto que el grupo Montoneros adoptó como su propia consigna. Cadáver zombi que cae y se levanta, no en la resurrección cristiana sino en la herejía biopolitizada y sacrílega. Eva se transmuta entre el cuerpo alhajado que encarna su presente y la reliquia que invisibiliza al cuerpo en la grafía del discurso, donde la veneración popular cristaliza su imagen en la soledad eterna y en la madre intercesora entre pueblo y líder. Madre 
horadada en el relicario vacío donde el oro y el oficio (a El, por El) traman la veladura parcial que corroe la materialidad excedente del cuerpo, la dosis necesaria para construir la fantasmática del cuerpo adorado y vituperado por partes, las que lo muestran como gema divina y las que lo ocultan en su evanescencia mística. La joya tiene su envés en los clavos y el estoque, desafiando desde la cureña a los acólitos y perjuros.

Los alucinógenos y el vudú van haciendo lo suyo respecto de la concreción de imágenes. Si la primera parte se titula "Zombi", al poema le siguen tres textos en prosa y un último poema con un epígrafe atribuído a Pedro Ara: "un valioso broche escudo peronista de piedras preciosas". La marca barroca de la gema irregular o la grafía neobarroca conceden la primacía al rótulo que Perlongher constituye como "neobarroso". Asimismo en esta serie se afirma la compleja unidad de lo que podríamos pensar como un poema único, donde la Nación está imbuída de la carga imaginaria (pero no menos real) que potencian los pliegues, telas y sayales. Entre la segunda y la tercera persona, se instala el viaje etnográfico que irrumpe dudando del mito y recelando del ritual. Antes hablé de sobrenaturaleza, de sobreabundancia de vida, como aspectos que constituyen el nudo de la forma poética en Perlongher. El punto donde estilo y sentido coinciden es la flexión política que insiste en la imagen oracular de la mujer patria. El cadáver no es simplemente el cuerpo en la cuenta regresiva de la descomposición. Flores y orquídeas se pudren lentamente como las ofrendas de los fieles que desfilan ante la cureña donde Eva yace embalsamada. Y quien mira desde lo alto de la muesca, inmutable a sus propios cortes y desgarros, es el rostro de la Nación. Semblante y vísceras, toda aura y tripas, ojos cerrados y mirada absorta, muerta inmortal como emblema metonímico del centro al "interior del país". Eva es santa y puta (Evita vive, del mismo Perlongher) por la memoria de su pueblo, pero también por el cilicio que atraviesa su soirée, sueño flotante por los clavos que traspasan su muslo como estigmas de un calvario crístico y tantálico. La vida y la naturaleza, acontecimientos efectivos del artificio, refuerzan el carácter alucinado y potente a través de los motivos que evocan una idea de sustancia orgánica, ligada a la textura vegetal. Así, el poder, el de la diosa fetichizada, el del médico demiurgo se desplazan como destinos cumplidos en presente continuo, sin que ceda la pregnancia sensible de la carne escayolada ante el cortejo fúnebre de la masa popular. Perlongher enfatiza los compuestos orgánicos al tiempo que los perfora con materia mineralizada, contrastando y combinando las texturas vegetales (harmalinas, lapas, mucílagos) con las operaciones de cortes y tajos esmerados que no alcanzan para librar el combate trascendental de la carne y "la sombra de esa mujer". Al decir de Nicolás Rosa, son los avatares de la etimología -cadere, caer- quienes convocan el envés del sentido, el oxímoron semiótico de la caída y la rigidez inmutable en la que insiste el embalsamamiento, simulacro (sentencia barroca) de perdurabilidad y el sepulcro, ícono inequívoco de todos los muertos, de 
Ella y la nada. Cuando en 1989, el poeta vuelve sobre Eva, escribe "El cadáver de la Nación". Texto segmentado en cuatro partes numeradas, el primero en verso y los tres restantes son poesía sin métrica, una noción que me parece más adecuada que hablar de prosa poética como si esto resaltara una estructura narrativa que expulsara la potencia del poema. El subtítulo "Zombi”; cadáver que cae y se levanta, pero no desde la resurrección crística; la santidad de Evita es sacrílega porque reafirma la herejía del rito profano, la conversión del cadáver en materia de cuerpo muerto y vivo a la vez. El zombi desafía el catolicismo de las altas esferas sociales que habiéndola odiado celebran su muerte en los salones y en las paredes de la ciudad'. Si "Viva el cáncer" es la venganza inscripta en las calles, el conjuro será el vudú, como magia negra, saliendo de los cauces porque enfatiza el oxímoron del cuerpo yacente y poderoso. De esta manera, Perlongher inscribe el trazo atemporal, inherente al mito, en la instancia embrionaria donde la Señora entra en la inmortalidad, formando una constelación serial con las marcas identitarias de la Nación. "Fundación Primera", "Pedro Ara", "muchedumbre", "entierro", "los peronios, sus súbditos", funcionan como claves de un imaginario histórico y cultural. Asimismo, el estuche/cajón que atesora la joya cadáver, encierra el valor supremo y profanado, la adoración y el salvajismo. De este modo, Perlongher pasa de la historia a la mitología suspendiendo la muerte de la heroína madre de la nación. Auténtica declinación sintáctica de la materia verbal, prosa y poesía desafían al silencio, cuya figuración petrificada en la fijeza enjoyada de la momia, traduce el resto alegórico como potencia redentora para la eternidad. El rostro áureo, el cuerpo alhajado de la muerta viva, se funden en la historia nacional, reinventándose como ícono en su grandeza diseminada.

En la flexión del trazo onomástico y en la imagen textual de los usos revertidos en abstracciones, se juega una de las matrices fundantes de la poesía de Osvaldo Lamborghini, allí donde se reducen al mínimo los nexos motivados entre palabra e imagen. Mas próximo a la música pensada en la construcción de la frase, la sintaxis toma la delantera para escuchar las figuras devenidas del ritmo, en la instancia literal del juego y de la forma. En Osvaldo, no hay significado ni sentido previo ni exterior a la escritura poética; así es como funciona una literalidad en tanto noción aparejada en términos de una poesía que en Lamborghini puede definirse como sistema de analogías truncas. O mejor: deliberadamente truncas, con el acento puesto en la voluntad creativa basada en la (aparente) destrucción de los nexos lógicos y causales. Para arriesgar una aserción, podría decirse que la poesía de Osvaldo Lamborghini asume una táctica de la inconsecuencia, cadena neobarroca, en su decir textual, de

1 PERLONGHER, Nestor. "El cadáver de la nación”, 1994, p. 116-127. 
motivos (fragmentariamente figurados) y de signos inmotivados que no responden a la potestad de antecedentes gramaticales. Sin embargo, Osvaldo no rehúye de lo que todo marco libresco supone; comienzos y finales en tanto conjunto de convenciones, los cuales, la escritura de Osvaldo destaca como apoteótico, inicio que entraña núcleos barrocos y neogauchescos sobre la trama de un misterio original:

"Entre lo racial y lo pedernal/Pringles/Entre lo social y lo pedernal:/'bla, ayer vino una señora...italiana..../liana/Y cada apóstrofe, Silence,/es una mención men(diga)a, a la(/Culpa”. ${ }^{2}$ La referencia espacial, apodíctica y concreta, contradice y desajusta la descripción atributos y propiedades neutras: "lo". Ni cuantificación ni tangibilidad. El neutro ratifica la condición inabarcable, desmesurada, sin efectos previamente asignables entre la raza y la resistencia, la sociedad y la dureza. Es en la conjunción copulativa donde se instala el oxímoron de una articulación que desvía y desajusta; la eficacia estética de la repetición que insiste y potencia el inmediato desplazamiento. Y en cierta forma, la poesía de Osvaldo (otra vez dice, nombra "lo pedernal"), la dureza. Pero sobre todo, la señal concreta y estable, Pringles, termina por contradecir, inesperadamente, o por simple oposición de secuelas, convirtiéndose en la extrañada viñeta de un espacio sin nombre posible. El neobarroco instala ese juego de contrastes entre lo específico y la abstracción desatinada de lo que se escapa a la aprehensión, a la comprensión inteligible, a la nominación razonable. Lo que resiste duro, es el resto y en su durabilidad se juegan los cortes de sonidos, de palabras a medio decir, de suspensiones, de signos incompletos. El apóstrofe introduce un vacío donde el corte cifra el fragmento y a su vez, una totalidad sin sentido asignado, donde la contigüidad simbólica habilita una constelación de palabras o mejor, significantes. En principio, podemos aducir que la noción del lenguaje y la escritura en Lamborghini destituye cualquier resabio trascendental, lo metafísico desde una operación concreta. El poema dice lo que es: un retazo de papel que graba el deseo sin ilusión (la ilusión como idea de un concepto) porque el enigma es el del misterio verbalizado, el del lenguaje que lleva el presente hacia adelante para que, sin embargo, la medida del tiempo siga siendo ese aquí y ahora. Esa sería la "traducción" de una figura que no traspasa el límite del presente, móvil (porque discurre y se desplaza) inmóvil (porque vuelve al punto de partida, transformado en restos de máscaras. La escritura "dice" que el trazo remite al sentido pero el acto de trazar se descompone y desvía. Así, el poema se detiene en la microscopía de un sufijo:

2 LAMBORGHINI, Osvaldo. "Pringles, 533" bla", 1997, p.7. 
"azarlo", no en su acepción de fortuna sino de cocción.

como se hace con el hijo prefe-

/rido

O ¡hum, que rico! Con el bebe mas comestible:

Porque hoy -youratentionplease-

Es 1981 de un jueves

Especial, atrevámonos: fe

(pero no de golpe) febrero 5

Igual a como empieza

El enigmático 'bla de 5

3

3.

Más adelante, el sujeto de enunciación veta la posibilidad de la ilusión con la excepción explícita de aquellos que puedan sumergirse en la turbia materia del barro. Pero "embarrarse" supone nadar en las aguas de un apócrifo misterio del "bagre". Nadar o embarcarse en la promesa fraudulenta de transparencia y comunicabilidad. La negatividad de todo lenguaje realista y referencial (postulado fundante del proyecto Literal) pone en marcha la concepción filosófica teórica que ofició de marco de formación intelectual para Osvaldo Lamborghini: el psicoanálisis lacaniano, a través de los cursos tomados con Oscar Masotta. La imposibilidad de ilusión clausura la evasión onírica, la patraña idealista porque el ensueño elevado y narcótico se extingue en el barro del lenguaje provocando turbulencias entre la significación y el significante. No hay anhelo ni fantasía inherente a la ilusión, sino la potencia “capaz de soportar" el "barro". La aparente cualidad de fuerza es solo el disfraz que cubre el otro disfraz, el de las palabras que vagan en cadena de asociaciones negativas (es decir, sin admisiones lógicas previas). La firma de autor "O. Lamborghini" inscribe la presencia improbable de huellas identitarias (lo individual, lo familiar, lo cultural, lo nacional, lo popular). La rúbrica constata eso que queda como presencia residual, como deseo de prescribir la repetición fragmentaria de jergas y códigos desorganizados, fuera de lugar. La poesía de Lamborghini se manifiesta como lenguaje gerenciado, pronunciando palabras como ecos y resonancias exhumadas, cuya novedad coincide con los restos de un pasado, un origen o mejor, una genealogía. Es aquí mismo donde se pone a prueba la eficacia de la letra para mostrar (y desmontar) en su gestación, el sistema de valores inherente al binarismo logocéntrico. Asimismo, el exceso de las palabras extraviadas, en el prisma indescifrable del conjunto, se juegan en los préstamos fallidos de refranes, lugares comunes, polémicas ya oídas y hasta construcciones sintácticas que rememoran la deliberada "intención" de creación estética (el hipérbaton). Todo desfondado desde el vacío de los fundamentos, la topología sin niveles ni distinciones conceptuales. Sin la mediación dialéctica de la distancia, el título afirma la paradójica coincidencia del 
goce y del fracaso. El canto de amor y duelo donde la posición de uno u otro no hace sino refrendar la circulación y el intercambio del nombre y del yo, que en el texto se convierte en significado de otro significante. El nombre es propio pero también sello familiar y más aún, firma compartida de poéticas hermanadas (literalmente hermanadas!) en la injundia festiva del despojo del canon; pero más aún, en la furiosa algarabía ante la tradición desollada en su blasón nacional. Lamborghini celebra la potencia productiva del saqueo, de uso y de traición. "Lamborghini" es anverso de "barro" generando el orden que asegura el intercambio, ante la ley en su presencia y en su inmediata necesidad de transgresión. El trazo, en la poética literal de O. Lamborghini, funciona como aspersión y absorción de individualidades marginales, restos de propiedades y atributos como restos identitarios, en el espacio asocial de la escritura. En esta línea, "Lamborghini" y "Pringles" condensan la referencialidad en su fragmentación en tanto elementos simultáneos erigidos desde el ritual del culto a la palabra. "Lamborghini" y "Pringles" se inscriben como "máquinas de poetizar" motivos que ponen a prueba la eficacia lúdica de las designaciones nacionales. Y así, el "Diantre" (reverso de "bicho Tadeo") que contrabandea y calumnia (sentidos, morales, razones) trenza, coloquial, el pelo de "m’hijita"; allí resuena el contrapunto ajetreado con la deformada payada del Sabio Blanco y del Sabio Negro, que en su hermano Leónidas toma forma del Martin Fierro pero también, de la escena del electroshock determinado en un fraseo incompleto y equívoco en "Las diez escenas del paciente" de El solicitante descolocado: "loco sí, boludo no". ADN de préstamos y transferencias encubiertas sobre el espacio sin propiedad de la escritura; eso es el secreto acuerdo del diantre y la risa negra (en Osvaldo y en Leónidas respectivamente), anudados en la lengua empañada y sexual de las nuevas versiones gauchas. Desde esta línea, podemos pensar cómo avanza la imagen de la letra en la firma (literalmente, el "dibujo" del nombre propio Osvaldo Lamborghini), la visualidad del grafo, que textualmente, propone dos posturas: "la firma es Telón”, según grita el público del Teatro Proletario, y la firma es interrupción. Esto es; los "chongos" de la "popular" quienes dan pie al nombre como fin o remate trasero. $\mathrm{O}$ como recita el sujeto de enunciación asumiendo una primera persona, la firma es "breva de descanso/fresa del camerino". Pausa del regodeo narcisista, el yo rubrica su propio aplazamiento y allí reinscribe el paso diferido de la temporalidad escrita. Lo literal se encuadra en la imagen inagotable que sin embargo no excede el sitio de la letra, siendo precisamente allí donde lo real se postula al infinito y como apariencia incontrastable de lo visible en la sílaba, su efecto y su acción. "Pez tiene una sola sílaba/El pez nada/una sílaba nada". En los versos que siguen a la cita entrecomillada, el silogismo continúa un punto de inicio el discurrir de un "arte poética" de un lenguaje exonerado de la culpa. Quiero decir: la lengua poética no paga tributo con algún sentido estable, ni contrae deuda 
responsable de algún crédito semántico diferido en el tiempo. Lamborghini prescribe la pauta literal como programa artístico sellando su acuerdo con la inmediación material, la presencia súbita y repentina de los desplazamientos significantes. Los versos continúan, entonces, el discurrir de una suerte de "arte poética", fechada en 1981 en la localidad de Pringles. Lo referencial actúa como contraparte concreta y singular de un sentido que permanece, no obstante, enigmático. La temporalidad signada, como un jueves de febrero en la dirección (literalmente, el sentido) de Stegmann 553, inscriben la calle y casa que alberga el aquí y ahora de la escritura, en tanto texto que indica sus propias condiciones de producción. Como frases o palabras fraccionadas, la poesía desfonda la significación monolítica desplazando al sentido como materia significante. Sean citas embragues (variación de géneros y textos, caso de "es la vida" en alusión al tango; estribillos o leitmotivs ("crisis del alba"); registros onomatopéyicos de una grafía fonológica que juega con la mímesis de sonidos sin traducción ("clanc, clanc"). Es la búsqueda de la forma y del ritmo lo que la lengua reparte y negocia en tanto objetivación poética que no va más allá de su imagen inscripta y de su sonoridad. Aquí se juegan las series combinatorias que disuelven y encadenan, paradójicamente, a la familia, la ley y el saber, en una fatalidad ciega para que en lugar de una traducción razonable se imponga una mitología desaforada.

\section{Bibliografia}

ECHAVARREN, Roberto. "Um fervor neobarroco" en Lame. Campinas: Editora da Unicamp, 1994.

CANJI, Adrian; SIGANEVICH, Paula. Ensayos de Homenaje a Néstor Perlongher. Rosario: Beatriz Viterbo, 1996.

FERNANDEZ, Nancy. Ensayos críticos. Violencia y política en la literatura argentina, Alciòn: Còrdoba, 2020.

FERNANDEZ, Nancy. "Los cuerpos del peronismo. Guebel/Perlongher" en Edgardo H. Berg y Nancy Fernández (coord. y ed), Intervenciones. Mar del Plata: La bola editora/Unmdp, 2016.

FERRER, Christian; BAIGORRIA, Osvaldo. "Perlongher prosaico" en Néstor Perlongher, Prosa Plebeya, Buenos Aires: Colihue, 1997.

IRIARTE, Ignacio y FERNANDEZ, Nancy. Fumarolas de Jade. Las poéticas neobarrocas de SeveroSarduy y Arturo Carrera, Mar del Plata: Estanislao Balder, 2002.

IRIARTE, Ignacio. Del Concilio de Trento al Sida. Una historia del neobarroco. Buenos Aires: Prometeo, 2017. 
LAMBORGHINI, Osvaldo. Stegmann 533 bla y otros poemas, Buenos Aires: Mate, 1997.

PERLONGHER, Nestor. "Como reina que acaba", "El cadáver", "Herida pierna" en Austria-Hungria; "El cadáver de la Nación” en Oleado de Lamé. Campinas: Editora da Universidade Estadual de Campinas, 1994.

PERLONGHER, Nestor. Prosa plebeya. Buenos Aires: Colihue, 1997.

ROSA, Nicolás. Tratados sobre Nestor Perlongher. Buenos Aires: Ars editorial, 1997.

Submissão: $21 / 05 / 2020$

Aceite: $20 / 09 / 2020$

https://doi.org/10.5007/2176-8552.2020.e83223

Esta obra foi licenciada com uma Licença Creative Commons Atribuição-NãoComercial 4.0

Internacional. 